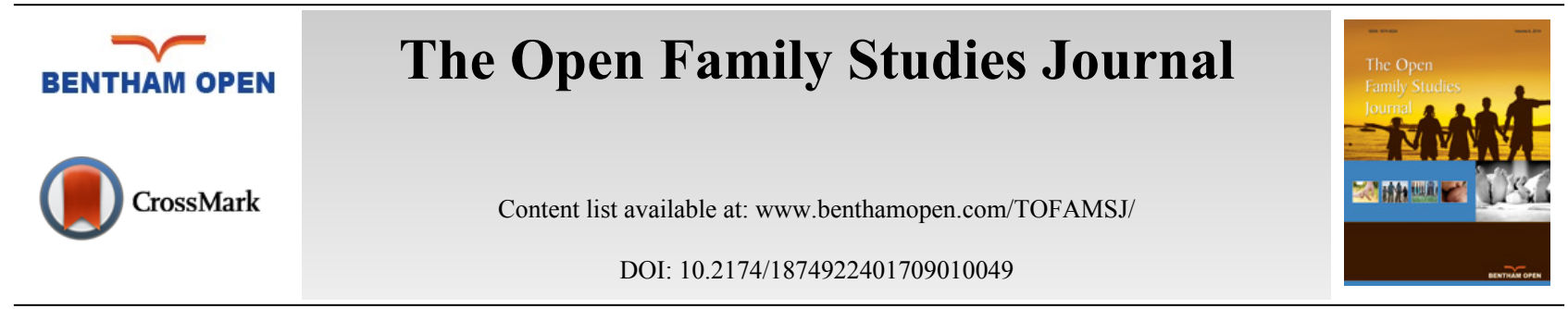

RESEARCH ARTICLE

\title{
Support for Children as Next of Kin and Systematic Follow up - Group Leaders' and Managers' Perspectives Within Non-profit Organizations in Sweden
}

\author{
Asa Carlsund ${ }^{1,2, *}$, Pauline Johansson ${ }^{2,3}$, Ulf Hammare ${ }^{2,4}$ and Elizabeth Hanson ${ }^{2,3}$ \\ ${ }^{I}$ Mid Sweden University Nursing Science, Sweden \\ ${ }^{2}$ Swedish Family Care Competence Centre, Kalmar, Sweden \\ ${ }^{3}$ Linneus University Kalmar, Sweden \\ ${ }^{4}$ Ersta Sköndal University College Stockholm, Sweden
}

Received: February 21, 2017

Revised: May 09, 2017

Accepted: May 12, 2017

\begin{abstract}
:
Method:

The aim of this study was to explore the systematic follow up of supportive activities in non-profit organizations targeted at children as next of kin. Managers and group leaders were interviewed, and findings were content analysed.

Result:

The findings indicated that a child focus, education, safety and trust were important. These factors were observed as the primary tasks and the key reason for being involved in supportive activities. Managers expressed concern about not retaining funding, if the organization was unable to demonstrate the effects of their activities. Namely, to enhance the health and wellbeing of children. In order to continuously develop their work most organisations explained that they used some form of system for follow up. However, there was a wide variation in how non-profit organizations worked with follow ups.
\end{abstract}

\section{Conclusion:}

Overall, it was evident that there was a major need for education and support in this area.

Keywords: Children as next of kin, Non-profit organizations, Supportive activities, Systematic follow up.

\section{INTRODUCTION}

When a parent has severe difficulties, the whole family is affected in one way or another [1 - 4]. Substance abuse, severe physical or mental illness, violence or death always bring consequences for the ones involved, and the children are especially vulnerable [5,6]. First, they are dependent on the affected parent as well as the other parent (if there is one). Second, depending on their own age and development the child might have difficulties in understanding what is happening as well as the causes. Previous studies show that children in these situations have an increased risk of being negatively affected i.e. by their parents' or own anxiety, changes in everyday life, excessive responsibility, lack of care or other difficult life experiences [5 - 8].

* Address correspondence to this author at the Mid Sweden University Nursing Science, Östersund, Sweden; E-mail: asa.carlsund@miun.se 


\section{BACKGROUND}

With reference to Swedish law and in the present study, children as next of kin refers to children (up to 18 years) with parents who suffer from mental illness, severe physical disability, and any form of substance abuse as well as children who have unexpectedly lost a parent or another adult with whom the child permanently lives [9, 10]. This includes children with caring responsibilities (comparable with the term 'young carers', [11]) as well as those without.

As a result of the Swedish legislative changes in 2010 [9] children as next of kin have gained increased attention. The aim of this amendment of the law was to emphasize the rights of the child and to strengthen the child perspective. Currently, the law focuses on children as next of kin and first and foremost, their need for and right to advice, support and information. In turn, the National Board of Health and Welfare Sweden (NBHWS) instigated a major development initiative to improve health and social care for affected children.

Between 13 and 17 percent of all children in Sweden experience having a parent with some sort of substance abuse $[8,12]$. Ten to fifteen percent of children have been exposed to violence $[8,3]$, up to 18 per cent live with a parent who suffers from severe physical disability, and approximately three percent have experienced the loss of a parent [8, 12]. Approximately, 30 percent of the children living with a parent suffering from substance abuse or mental illness left elementary school without being eligible to start high school, which in turn constitutes a risk factor for illness later in life $[8,12,13]$. In comparison, the proportion of children from families without such experiences is approximately 12 percent $[5,8,12]$.

Historically, Sweden has boasted a world-renowned welfare state model in which the State cares for its citizens from the cradle to the grave $[14,15]$. More recently, the Swedish model has undergone a substantial change. In the 1980s, the expansion of the Swedish welfare state ended, and in the 1990s, the economic crisis forced the government to reduce welfare services in order to decrease public spending. Although the service levels were restored in several areas during the 2000s, the public trust in welfare is no longer as steadfast as it once was $[15,16]$.

Alongside Swedish health and social care services, non-profit organizations provide advice, information and support for children as next of kin [6]. Non-profit organizations are categorized as civil society [17], but their works are usually regulated by health care or social service laws $[18,19]$. Due to a political decision in 2008 , a national agreement was established aimed at strengthening non-profit organizations' independence and strengthening their role as a voice of public opinion.

The underlying thinking was to create conditions for increased diversity in civil society, where the non-profit organizations were assumed to have an important role to play, i.e., to increase the diversity and number of actors in health and social care services [18]. Non-profit organizations are often referred to as flexible, i.e., the organization individualizes the concrete needs of help-seeking persons, and they also take particular responsibility for marginalized people [19, 20] emphasized closeness to the help-seeking individual, which in turn creates space for responsiveness [21, 22] underscored the informal and family-centred culture that is representative of non-profit organizations in which attitudes, relationships and solidarity hold prominent places [23].

Even though the situation for children as next of kin differs in many ways, their needs may be similar in several respects [6]. Children are at a significantly increased risk to be affected negatively if they are involved in incomprehensible situations in life, such as anxiety and unpredictable incidents [1,24]. The family economy, social relationships, communication and division of roles are additional examples of risk factors for the children affected [6]. Indeed, it has been well documented that children as next of kin are at increased risk for socio-economic problems, poor school performance and mental illness [8]. Although there are a number of organizations that provide support to these children, there is little knowledge of the results of the support given. The developmental necessity as well as the need for research is described as comprehensive [25]. This study forms part of a larger commissioned study conducted by the Swedish Family Care Competence Centre (SFCCC), a centre of excellence in the field of family or informal care (http://www.anhoriga.se/) on behalf of the NBHWS, which focuses on systematic follow up of supportive activities targeted at children as next of kin. The focus of the present study was the work of non-profit organizations in this area.

\section{AIM}

The aim of this study was to explore how non-profit organizations work with supportive group activities for children as next of kin and how they follow up obtained results. 


\section{METHODS}

A descriptive study with a convenience sample [26] was conducted in 2015. This study was carried out with a sample of managers and group leaders in non-profit organizations in Sweden who provide help in the form of advice, support and/or information (e.g., physical, emotional or practical) for children as next of kin. The data were collected through individual and group interviews.

\subsection{Sample and Process}

To be included, the non-profit organization had to provide help in the form of advice and/or support for children as next of kin (up to 18 years). They were not required to perform any form of systematic follow up prior to the study. An informal review of the non-profit organizations in Sweden was made via the Internet. Children got in touch with the non- profit organizations via information- giving at organized public lectures, through advertisements, social media and the internet.

Forty-seven organizations were identified and contacted by letter, email or phone call, and ten organizations agreed to participate. Managers and group leaders in the interested organizations received oral and written information about the study aims and process, and were asked to provide informed consent. A cooperation agreement was established that involved the organizations providing a contact person and time to participate in the study. For the researchers, the cooperation agreement meant supporting the staff; obtaining increased knowledge about systematic follow up; finding, developing, refining and evaluating items and/or questionnaires; and analyzing the results from the data collected by interviews. The participants were aged between 26 and 74 years, one-third of the participants were women. Many of the participants were educated or were undergoing education in psycho-social areas (e.g., social worker or psychologist).

\subsection{Data Collection}

The managers and the group leaders $(n=49)$ were interviewed in focus groups or individually [26], giving a total of 20 interviews. The interviews took place at the participants' work places. Open-ended questions were asked in semistructured interviews that lasted between 30 and 90 minutes each. The interviews were tape recorded and transcribed verbatim. The interviews included information about the organizations, background, goals, results of the support group activities and the managers' and the group leaders' encouragement to provide systematic follow up.

\subsection{Analysis}

The data collected were analyzed with conventional content analysis [27]. To avoid affecting the data through our own interpretations, the researchers tried to retain the integrity of the data as much as possible [28]. First, the data were read repeatedly to achieve immersion and gain a sense of the whole, the key thoughts and concepts were noted in order to derive codes. The codes were sorted into 14 subcategories based on how they were related to each other. The subcategories were then combined into five categories: "Goals related to systematic follow up", "Empowering each child", "Structured supportive group activities", "Current performed follow up work" and "Future follow up visions". During the analysis process, the categories were refined by repeatedly studying the interview text and revising the categories. The focus group interviews were analyzed on a group level [26], single quotations were used to highlight the categories that emerged. The interviews are numbered from 1 to 20 in the results, and M denotes "manager", and GL denotes "group leader".

\subsection{Ethical Considerations}

The ethical considerations were made on the basis of the guidelines from the Ethical Advisory Board in South East Sweden (http://www.bth.se/hal/eksydost.nsf/) and Swedish law [29]. There were no dependent relationships between the researchers and participants. The study was of such a nature that it would not harm the children in any way. No personal information from the children, supported by the non-profit organizations, was handled within the study. All collected data were treated confidentially, and participants were informed that they, could withdraw from the study at any time without further explanation.

\section{RESULTS}

The participating organizations $(n=10)$ were located in the middle and southern parts of Sweden. Most of the organizations offered their services within restricted geographical areas, whereas a few of them offered some of their services nationally through online chat or email facilities. Approximately half of the organizations have existed for 10 
years or more. Four out of ten organizations were run by faith-based organizations. The organizations have employees ranging from two up to approximately ten people. The participants described that their hours of working with the group activities were after school, on weekends and holidays and all year around.

All of the organizations offered group activities (for example group talk, discussion, sport, play or cultural event), always led by two group leaders for each activity (in concordance with the Children's Rights in Society), with predetermined themes in some way. The thematic areas focused on for instance guilt, shame, loneliness, the right to be a child, and children's rights in society. The number of gatherings differed from usually ten up to twenty three, and the age of the target group differed between six and eighteen years of age. Most organizations invited the children to participate in repeated group activities.

\subsection{Goals Related to Systematic Follow Up}

The participants described their organization goals in diverse ways. Some of them were fully aware of the objectives of the organization, whereas others described the goals vaguely. A few of them were unsure and imprecise when describing the organization's goals, some of the participants had disagreements regarding the goals. However, all participants were able to describe their organizations' goals in the form of practical conditions for the children such as providing a safe, calm and reliable place. They illustrated a willingness to help the children feel that they are welcome in any way, even though they may be sad or angry.

.... Our statutes... say our goals ... and our mission are.../... concrete, yes, but they are probably more obscure... We serve those who are ill and their families...//...yes, but it is for the best of the child to help the child get knowledge and to start talking, that's the goal! (M14)

\subsection{Empowering Each Child}

The participants considered the child perspective as the most important issue in their work. Their challenges were described as how to help the children function in their particular situations and how to help them move forward with their lives. All participants noted the importance of educating the children in how to actually say no, for instance, if they do not want to see their dad when he is drunk or if they do not want to do the laundry every day; this approach helps the children understand what it means to be a child and what are normal and abnormal responsibilities at a certain age.

...Some parents have been like this....yes, now they [the children] are protesting more and say no; they don't want to have that much responsibility at home anymore...//... and we consider that a positive response .... that we are strengthening the children's ability to say what they mean ... I don't want to do the washing anymore ... I'm only ten years old .... Or I don't want to take on the responsibility of bringing my siblings to and from pre-school. (M2)

Both the managers and the group leaders considered that they wanted the children to feel safe, have trust and receive support from an adult whom the children can trust in any situation.

Many children describe themselves as very lost, they have found it difficult to set limits, and they have found it difficult to say no. They find it difficult to look people in the eyes, but later you can see a great change as a result of their participation, that they bloom, and you can tell a lot about a child from that... (GL17)

As previously mentioned, the managers and group leaders try to help the children in structuring their lives, e.g., by educating the children in the rights of a child or their rights in the society.

We tell them stories from our own experiences to try to get them to understand that yes, we're talking about children's rights; did you know that you have rights? ... And then they can start thinking about themselves, begin putting words to their own stories, such as talking about how their mom says they have to pick up their little brother every day... (GL8) 
In addition, the managers tried to spread the organization's message in order to increase the children's awareness and understanding about children as next of kin and to lower their guilt and shame. Participants also illustrated that an absolutely essential way to lower their guilt and shame is to share their feelings with others and to discover that they are not alone in their particular situation.

...the aim of our organization, as it still is today, above all, is to remove the shame surrounding this problem and to talk about it. Because they're [the children] not alone, but the more they open up, the more others will open up as well. (M5)

\subsection{Structured Supportive Group Activities}

According to the group leaders, structure, predictability, order and tidiness were described as having special meaning, both to themselves and for the children. The participants described that they had learned the importance of activity structure in order to keep the participating children feeling safe and secure. The great importance of maintaining the same structure each and every time was underlined. One example of structure included first sharing a meal while chit-chatting, then preparing to perform an activity with a pre-determined theme, and last but not least, a performing pre-determined 'rounding off' activity.

$\ldots$ and we are of course consistent ... and completely structured in those things .... It's the same all the time and that's what makes them feel more secure (GL3)

Most participants described satisfaction with their child-supporting work. Both the managers and the group leaders believed they had a supporting, helping, developing and knowledge-sharing function. Further, they described feeling a sense of satisfaction when the children were satisfied with what the organization might offer. For instance, if a child needed additional support, the organizations had plans for helping the child in the form of contacting social services, health care entities or other authorities.

... And then we, with the youth, can make contact with the responsible social service office.... In some cases, the youth's desire may be to accompany them to the meeting ... if needed... (M4)

All participants clearly described the great engagement of the children participating in their group activities, and they wished to help children on their way to a functional daily life. Many of the participants talked about being flexible, which in turn may have meant that they do not strictly follow the established programme.

There must be flexibility when meeting with a group ... then, when you sit down in the group, you have to be flexible and see that one type of activity may not work every time ...// ... it's important not to think you have a template that you always have to follow ... you have to be flexible. (GL6)

Children need to be treated according to their needs, and their needs may be different. Participants from organizations working with children where the parent or another adult who the child permanently lives with unexpectedly dies illustrated that this situation, in many cases, may occur abruptly and unexpectedly for the children, e.g., by suicide. However, other participants described that the situation of the child, in many cases, may have been the same during the child's entire childhood, and for some children, it may have been perceived as a normal state.

We had this one guy here....his mother was really sick, really mentally ill. He didn't understand what he was doing here. "I have no sick mum," the boy said. We knew that was the case, but... (M15)

The activities were described as organized in ways that not only had to suit the children's situation but also had to suit the children's ages and levels of development. For instance, some children did not have the capability to describe their feelings; instead, they jumped up and down or hid underneath tables. Other children, from time to time, simply did 
not want to say or express anything in the group and that was okay. This, in turn, meant that the group leaders did not know much about each child's situation. However, the group leaders described that these children participated and listened to what was said during the group activity. Subsequently, the children could communicate by role play or using Casper dolls.

...If they feel the need, they may whisper what they want to say, because it's such an important part of... the basis to why we are here. We need to share, but then it's okay to say no; those who are not able to talk or, don't want to talk at that moment, then it's okay for them to say no, but they always get a chance... (GL9)

\subsection{Current Performed Follow Up Work}

Most participants claimed that they performed some sort of practical follow up, e.g., oral discussions, with the children as well as their parents. They also stated that they had to ensure closure in order to try to help the next child, i.e., "move on", aiming to help as many children as possible.

We must let the children move on ... so the follow up is similar to a family gathering (M19).

The participants described that their organizations had some sort of documentation system to continuously develop their work. A few participants illustrated anonymized temporary documentation of each child with written consent from the children's parents. All of the participants stated that such information was always deleted when each group activity ended. They also illustrated confusion and frustration regarding documentation, and legal rights and/or options were described as unclear and messy. In some cases, documentation was described as important, for instance, when showing the organization's development statistics and figures to contributors.

We have gathered some information, but we try to limit it as much as possible; we do not think we are under any legislation that says we are allowed to do so. Ehh, we all know that psychologists and therapists must do this as well. (M10)

Approximately half of the group leaders did not know if their organization carried out follow ups. One-third of the participants described that they used questionnaires the first time the children participated. The majority of participants asked questions immediately prior to the group activity in various ways. They also explained that the first time the children answer, they say they feel good because they think that is what is expected. However, as time goes by, the children express themselves (by words) as increasingly angry, shameful, sad and unstable, which the group leaders described as more consistent with how the group leaders actually perceive the children. Three organizations performed follow ups in the midst of their group activities, and participants from these organizations described the same pattern with the children's decreased mental health. Moreover, the participants indicated that it surely is an important result when the children begin to talk and maybe even discuss with each other. Continuous oral discussions were described as natural components of the group activities.

... It would be satisfying to have follow up that's more continuous; it would be satisfying to, during a longer period of time, compile anonymized material that shows what the results of these group activities mean as well as the resources required. (GL12)

Despite the above-mentioned elements, most of the group leaders described that they experienced important child developmental results during the group sessions and as an accumulated result throughout the term. However, they found it difficult to measure and show others their results. Additionally, they believed that there were several difficulties when following up their activities. An example they describe is that they continuously talked to the children about the fact that the group activity was the start of ongoing work with them; this, in turn, made it difficult to measure follow up correctly. Participants also talked about factors such as the children's ages and development that affected how they might respond to a follow up. Another problem described was that in order to understand and interpret the children's 
answers, one must link the answers to their background, i.e., each child had different childhood conditions, and it can be difficult to use standardized questionnaires for all children or to generalize their answers.

You can't just put it [these data] into a system for all of the children ... because you have no clue about their backgrounds, which are needed to understand these data as well. (GL18)

Most participants stated that they sought to provide evidence of the benefit of their particular group activity, which preferably should be easy to achieve, and then in turn show others.

...Yes, I think it will feel good to get past this, because it's a little disorganized, this whole thing ... We have never compiled our questionnaires; they are just lying around in bundles. (M14)

The participants illustrated that they constantly, based on everyday experiences, made changes in their way of performing the group activities. They clearly portrayed how, by conversation, they gathered background information and captured the children's signals of fear, anger or sadness. Further, the participants tried to explain how these conversations were often followed up at the end of group activities, regularly in the form of simple written evaluations.

... They tell us a lot, which in turn tells us a lot about their experience here. We make a sort of reconciliation with them in that we ask them their expectations for the rest of the time, now that half the time has gone. It could be difficult to know what it means to be here when first arriving here. (GL20)

The most common method of follow up was described as "homemade" questions on a piece of paper, which were saved and stored on a shelf. A few participants described that their organization made their follow ups electronically. The children answered predetermined questions before they participated in the group activity, and then the children repeated the same process after six months and at the end of the group activity. One organization had performed systematic follow up work for several years. This organisation routinely administered the following questionnaires: Becks Youth Scales [30], The Ladder of Life [31], Children are People Too [32], Strengths and Difficulties Questionnaire [33] and the Sense of Coherence Scale [34]. The participating children (children $>$ seven years old) responded to one or more questionnaires adjacent to the group activity, and then the children repeated the same process at the end of the group activity.

\subsection{Future Follow Up Visions}

The majority of the managers stated that they wanted to be able to present what they actually achieved and to show that their way to offer help and support was effective. Most managers described great concern about not retaining funding if they were not able to demonstrate their good work in the aim of increasing the health and wellbeing of children. They spoke enthusiastically about the absolute necessity of follow up work for their future survival.

... I believe that it's necessary to do this; if we want to continue, I am convinced that we must be able to present our progress in some way to the system were we get the money from. (M13)

The importance of showing others the organization's results and its achieved goals were acknowledge as increasingly important. Additionally, participants from well-established organizations illustrated the complexity and difficulty in actually showing what the organization achieved in each participating child's life. They wanted to able to show that the things happening in these children's lives actually are good and positive for them. For instance, the municipality sometimes requested statistics on the results of the activities that they provided in grants, such as how many of the children were in the group activities due to parental substance abuse, mental illness, among other issues. The participating managers had investigated how to present their results in a proper and illustrative way. However, none believed that they had found the optimal instrument with which to do so. Nevertheless, they illustrate willingness and hope to learn more about systematic follow up. 
... In our organization...now that we have started writing reports and looking at different types of statistics, we have noticed that there are questions that we have not asked previously or we have not previously documented that we should document. (M11)

Most participants claimed that they performed some sort of follow up, but most stated that they were not satisfied. Their suggestion was that the follow up ought to be easy to perform, clear, and simple and that it could be stored in a simple way. Other participants said that they would like newer, simpler instruments. One of the participants spoke of the instruments that they use currently, but said that these instruments were too broad and that they also demanded too much of the child.

Nevertheless, many participants considered their organization to be in urgent need of functional ways to follow up on their supportive group activities. One common opinion was that the participants wanted an easy and user-friendly follow up questionnaire that gave them the ability to view results from their organization and provide them to their financiers.

...If there was a pre-written questionnaire, we would be very happy. (GL20)

\section{DISCUSSION}

Our results describe several different types of formulating supportive activities for children as next of kin. The results also reveal great differences in how different non-profit organizations work with follow ups.

Structure, predictability, order and tidiness were stated as important and meaningful in the supportive group activities for children as next of kin. At the same time, flexibility for each group of children and every new situation was also widely presented. Further, child focus, education, safety and trust were important; these factors were observed as the absolute main tasks and the reasons for being involved in that particular organization. Earlier studies have also shown that children's knowledge and understanding regarding their family situation have a crucial impact on how they further are able to handle the situation $[35,36]$. In line with the present results, previous studies have emphasized the importance of the professional's role in age-appropriate communication and integration with children as next of kin [2, $37,38]$ highlighted the lack of supportive activities for children as next of kin and indicated that these activities need to be further developed and evaluated. In our study, the participants experienced important child developmental results from their supportive activities. However, they found it challenging to measure what they had achieved and also experienced difficulty in showing others in an appropriate and clear manner. The results further revealed that the participants found it difficult to generalize the answers from the follow ups, and they also illustrated great confusion regarding documentation and expressed concern about not retaining funding due to deficiencies in their presentation techniques. In some organisations follow ups were used first and foremost to continuously follow child development, develop their work and show others their group support results. In concordance with Söderlind [39] participants described problems such as child stigmatization, lack of time, lack of meaning or relevance for the organizations' goals when using questionnaires. On the other hand Glad et al. [40], reported that focus had shifted from costly follow ups to actually seeing and understanding the value of follow ups at both individual and group levels.

In line with Hansson [5], we found that systematic follow up on an individual and group level was carried out to a very limited extent. Often, there was a lack of systematic documentation of goals, content and results, which in turn could impact future quality and organization development. At the same time, the organizations showed a moral as well as ethical obligation to ensure that the supportive activities they offer children as next of kin are suitable and of good quality [39].

Finally, follow up was described as very important for producing the best for children as next of kin and for developing their practical daily work. However, another main issue in accomplishing systematic follow up is to show the results to policy makers and possible contributors. We identified several different ways to manage and perform systematic follow ups in non-profit organizations. Nevertheless, the participants expressed a large and clear need for education on the subject of systematic follow up, and many participants asked for a simple, short and useful instrument to aid in follow up. During this study, we did not identify any validated instruments that matched these organizations' requests and needs.

We regard our study as useful for exploring how non-profit organizations work with and support children as next of 
kin and how they follow up the results of the support activities they provide. Twenty interviews with a total of 49 participants were deemed an adequate sample size for variation in organizations and participants [26]. With a convenience sample, the participants were self-selected into the study by responding directly to the authors. Those who chose to participate may well have been those most interested, negatively or positively, by their experience of systematic follow up and therefore with the most commitment, interest in and opinion on this topic. Although this may be the case, the open and reflective narratives (on average, 50 minutes) revealed valuable insights, about the organizations and their support for children as next of kin and how they work with follow up. However, we interviewed managers and group leaders separately, and the interviews were tape-recorded and transcribed verbatim, and the categories were checked against the original data. Moreover, representative citations confirmed the descriptions, which ensured the credibility of the results [26].

\section{CONCLUSION}

With this research project, the SFCCC began work to support non-profit organizations in developing the systematic follow up of supportive activities for children as next of kin. The organizations involved have a large burden of work and have limited resources for this work. Meanwhile, the children targeted by these organizations are increasing in number. Several other organizations are still in need of support, and staff working to give children support require additional knowledge about systematic follow up. Furthermore, there is still a large gap in the knowledge regarding the affected child's position in systematic follow up. The children's valuable opinions should be captured. Therefore, politicians and policy makers must be made aware that interventions for work with systematic follow up need to be accelerated. Indeed, we have only just scratched the surface, and much work remains. Together with different stakeholders, the SFCCC aims to create a meaningful, evidence-based systematic follow up method. Therefore, the current study must be followed by additional research and development work together with voluntary organizations.

\section{ETHICS APPROVAL AND CONSENT TO PARTICIPATE}

Not applicable.

\section{HUMAN AND ANIMAL RIGHTS}

No Animals/Humans were used for studies that are base of this research.

\section{CONSENT FOR PUBLICATION}

Not applicable.

\section{CONFLICT OF INTEREST}

The authors declare no conflict of interest, financial or otherwise.

\section{ACKONWLEDGEMENTS}

Declared none.

\section{REFERENCES}

[1] Brent DA, Melhem NM, Masten AS, Porta G, Payne MW. Longitudinal effects of parental bereavement on adolescent developmental competence. J Clin Child Adolesc Psychol 2012; 41(6): 778-91.

[http://dx.doi.org/10.1080/15374416.2012.717871] [PMID: 23009724]

[2] Wong M, Ratner J, Gladstone KA, Davtyan A, Koopman C. Children's perceived social support after a parent is diagnosed with cancer. J Clin Psychol Med Settings 2010; 17(2): 77-86.

[http://dx.doi.org/10.1007/s10880-010-9187-2] [PMID: 20169402]

[3] Annerbäck EM, Wingren G, Svedin CG, Gustafsson PA. Prevalence and characteristics of child physical abuse in Sweden - findings from a population-based youth survey. Acta Paediatr 2010; 99(8): 1229-36. [http://dx.doi.org/10.1111/j.1651-2227.2010.01792.x] [PMID: 20219025]

[4] Maier EH, Lachman ME. Consequences of early parental loss and separation for health and well-being in midlife. Int J Behav Dev 2000; 24(2): 183-9.

[http://dx.doi.org/10.1080/016502500383304]

[5] Hansson M. Proper support to children in families with addicition and other major dificulties. Interim report of a government comission. Socialstyrelsen: In: Stockholm. 2014. 
[6] National Board of Health and Welfare Sweden Children as next of kin Consequences and needs when parents have serious difficulties, or passes away Socialstyrelsen: Stockholm $2013 . \quad$ at: http://www.socialstyrelsen.se/Lists/Artikelkatalog/Attachments/19114/2013-6-6.pdf

[7] Gladstone BM, Boydell KM, Seeman MV, McKeever PD. Children's experiences of parental mental illness: a literature review. Early Interv Psychiatry 2011; 5(4): 271-89. [http://dx.doi.org/10.1111/j.1751-7893.2011.00287.x] [PMID: 21883973]

[8] Hjern A, Berg L, Rostila M, Vinnerljung B. Children as next of kin. How is school? Kalmar: In: Nationellt Kompetenscentrum Anhöriga. 2013.

[9] Ministry of Health and Social Affairs Law amending the healthcare. In: Svensk författningssamling: Socialdepartementet. 2009.

[10] Ministry of Health and Social Affairs. Law of patient safety 2010:659. In: Regeringskansliet/Lagrummet: Social departementet. 2010.

[11] Becker S. Global perspectives on children's unpaid caregiving in the family: Research and policy on 'young carers' in the UK, Australia, the USA and Sub -Saharan Africa. Glob Soc Policy 2007; 7(1): 23-50. [http://dx.doi.org/10.1177/1468018107073892]

[12] Hjern A, Manhica HA. Children as next of kin to patients in hospitals- How many are they? Report 1 from the project "Children as next of kin"- a survey (In Swedish). Kalmar: Nationellt Kompetenscentrum Anhöriga. 2013.

[13] Public Health Agency of Sweden, 2009 [Children in families with alchohol and narcotic abuse] Östersund Public Health Agency of Sweden. 2009.

[14] Esping-Andersen G. A welfare state for the twenty-first century. In: Pierson C, Castles FG, Eds. The Welfare State Reader. Cambridge: Polity Publishing House 2006.

[15] Edlund J. Trust in the capability of the welfare state and general welfare state support: Sweden 1997-2002. Acta Sociologica 2006; 49: $395-417$. [http://dx.doi.org/10.1177/0001699306071681]

[16] Larsson B, Letell M, Thörn H. Transformations of the Swedish welfare state from social engineering to governance?. New York, NY: Macmillan Palgrave 2012. [http://dx.doi.org/10.1057/9780230363953]

[17] Elson PR. Ties that bind? An empirical exploration of values in the voluntary sector: value importance, hierarchy and consensus in the in the independent hospices in the UK. In: Kumar S, Ed. Voluntary Sector Working Paper 2. London: London School of Economics 2006.

[18] Sjöbratt K. A welfare state for the twenty-first century In The Welfare State Reader. Cambridge: Polity Publishing House: 2010.

[19] Salamon LM, Hems LC, Chinnock K. Nonprofit sector: for what and for whom? Working papers of the Johns Hopkins comparative nonprofit sector project. Stockholm: Center for Civil Society Studies 2000; 37.

[20] Blennberger E. Begrepp och modeller SOU 1993:83 Frivilligt socialt arbete Kartläggning och kunskapsöversikt Rapport av socialtjänstkommittén. Stockholm: Fritzes 1993.

[21] Sherman AL. Faith in communities: a solid investment. Society 2003; 40: 19-26. [http://dx.doi.org/10.1007/s12115-003-1048-2]

[22] Austin MJ, Claassen J. Implementing evidence-based practice in human service organizations: preliminary lessons from the frontlines. J Evidence-Based Soc Work 2008; 5(1-2): 271-93. [http://dx.doi.org/10.1300/J394v05n01_10] [PMID: 19064451]

[23] Nordfeldt M, Söderholm J. Voluntary organisations as contractors. Stockholm: Socialstyrelsen: 2002. what does this mean for users?

[24] Lin F-G, Lin J-D, Hsieh Y-H, Chang C-Y. Quarrelsome family environment as an enhanced factor on child suicidal ideation. Res Dev Disabil 2014; 35(12): 3245-53. [http://dx.doi.org/10.1016/j.ridd.2014.08.007] [PMID: 25178707]

[25] Axberg U. Identification and discussion paper. Göteborg: Fou Väst 2014. [Methods for systematic follow up of interventions aimed at children, adolecents and their families.]

[26] Polit DF, Beck C. Nursing Research: Generating and Assessing Evidence for Nursing Practice. Philadelphia: Lippincott Williams and Wilkins 2012 .

[27] Hsieh HF, Shannon SE. Three approaches to qualitative content analysis. Qual Health Res 2005; 15(9): $1277-88$. [http://dx.doi.org/10.1177/1049732305276687] [PMID: 16204405]

[28] Sandelowski M. What's in a name? Qualitative description revisited. Res Nurs Health 2010; 33(1): 77-84. [PMID: 20014004]

[29] Ministry of Health and Social Affairs. The law on ethical review of research involving humans] Svensk författningssamling: Socialdepartementet 2003.

[30] Beck JS, Beck AT, Jolly JB. Beck youth inventories. San Antonio: Psychological Corporation 2005.

[31] Cantril H. The pattern of human concerns. New Brunswick, NJ: Rutgers University Press 1965. 
[32] Lerner R, Naiditch B. Children are people too! Chemical abuse prevention programs Support group training manual Hawthorne, T, red. St Paul, Minnesota: Children Are People, Inc. 1985.

[33] Goodman R, Meltzer H, Bailey V. The Strengths and Difficulties Questionnaire: a pilot study on the validity of the self-report version. Eur Child Adolesc Psychiatry 1998; 7(3): 125-30.

[http://dx.doi.org/10.1007/s007870050057] [PMID: 9826298]

[34] Antonovsky A. The structure and properties of the sense of coherence scale. Soc Sci Med 1993; 36(6): 725-33. [http://dx.doi.org/10.1016/0277-9536(93)90033-Z] [PMID: 8480217]

[35] Davey MP, Tubbs CY, Kissil K, Niño A. 'We are survivors too': African-American youths' experiences of coping with parental breast cancer. Psychooncology 2011; 20(1): 77-87. [http://dx.doi.org/10.1002/pon.1712] [PMID: 20198717]

[36] Jakobsen IS, Christiansen E. Young people's risk of suicide attempts in relation to parental death: a population-based register study. J Child Psychol Psychiatry 2011; 52(2): 176-83. [http://dx.doi.org/10.1111/j.1469-7610.2010.02298.x] [PMID: 21039482]

[37] Turner J. Children's and family needs of young women with advanced breast cancer: a review. Palliat Support Care 2004; 2 (1): 55-64. [http://dx.doi.org/10.1017/S1478951504040076] [PMID: 16594235]

[38] Niemelä M, Väisänen L, Marshall C, Hakko H, Räsänen S. The experiences of mental health professionals using structured family-centered interventions to support children of cancer patients. Cancer Nurs 2010; 33(6): E18-27. [http://dx.doi.org/10.1097/NCC.0b013e3181ddfcb5] [PMID: 20555258]

[39] Söderlind M. [Support for structured follow up] Socialhögskolan: Lunds universitet Turner J 2004 Children's and family needs of young women with advanced breast cancer: a review Palliative and Supportive Care 2: 2012; 55-64.

[40] Glad J, Nybom J, Nyström S, Eskel-Grönberg M, Lindqvist P, Ljunggren S. [Systematic follow up Descriptions and example]. Stockholm.: Socialstyrelsen 2014 .

\section{(C) 2017 Carlsund et al.}

This is an open access article distributed under the terms of the Creative Commons Attribution 4.0 International Public License (CC-BY 4.0), a copy of which is available at: https://creativecommons.org/licenses/by/4.0/legalcode. This license permits unrestricted use, distribution, and reproduction in any medium, provided the original author and source are credited. 